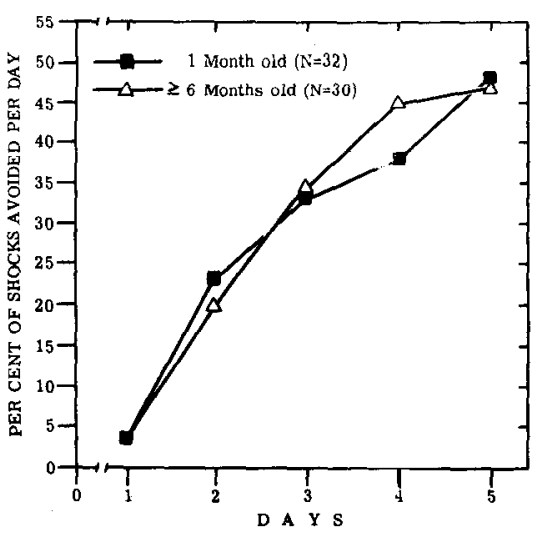

Fig. 2. Avoidance performance of female mice of different ages $(\mathrm{N}=$ number of groups of five mice each).

of the first shock. It is therefore concluded that all avoidances performed by the Ss are the net result of memory of the previous. trial or trials, and not due to spontaneous tendencies or handling. This view is further supported by the very low level of avoidance achieved throughout the first day of trials, even after the mice had received more than one shock to the feet.

The possibility that the differences in the levels of acquisition or retention of the various age groups may be the result of a differential sensitivity to the shock is ruled out by the observation that, with only a few exceptions, all Ss studied escaped from the "well" within $2 \mathrm{sec}$ of the onset of the shock. Any differences in sensitivity to the shock between the age groups or sexes would have been reflected in differences in escape latencies. Furthermore, no observable difficulty could be detected with regards to the ability of any of the age groups to escape from the "well." Physical performance, therefore, played essentially no part in the recorded differences in levels of learning among the various groups.

It is not known at the present time why young, 1-month-old female mice consistently performed substantially better than their male counterparts a phenomenon previously demonstrated in rats by Levine \& Broadhurst (1963)], nor is there an explanation for the failure to demonstrate age-related differences in performance in the female $S s$ in this experimental setup. The possible involvement of the sex hormones in brain maturation is suggested by the work of Curry \& Heim (1966), who demonstrated that postnatal administration of estradiol to female rats resulted in an early laying down of the myelin sheath around nerve fibers in the brain. Although the nature of this mechanism is not elucidated, it is possible that estradiol, both endogenously as well as exogenously administered, by accelerating the process of myelination, may enhance functional brain maturation. Furthermore, Beatty \& Beatty (1970) showed tilat female rats receiving testosterone both in infancy and in adulthood exhibited the inferior avoidance performance characteristic of males in an active-avoidance situation.

A possible alternative explanation for the inferior performance of the 1-month-old male mice, as compared to their female counterparts in this study, is suggested by the observation (Kulkarni \& Rahwan, unpublished data) that male mice tend to exhibit a "freezing" tendency if the same training paradigm described above is intensified by shortening the intertrial intervals. This incompatible behavior is not appreciably evident in the females. Accordingly, the possibility cannot be ruled out that some degree of "freezing," although not grossly discernible in the present design, may have contributed to the inferior performance of the young males, as compared to the females.

\section{REFERENCES}

BEATTY, W. W., \& BEATTY, P. A. Effects of neonatal testosterone on the acquisition of an' active avoidance response in genotypically female rats. Psychonomic Science, 1970, 19, 315-316.

BRUNNER, R. L. Age differences in one-trial avoidance learning. Psychonomic Science, $1969,14,134-136$.

CURRY, J. J., \& HEIM, L. M. Brain myelination after neonatal administration of eastradiol. Nature, 1966, 209, 915-916.

LEVINE, S., \& BROADHURST, P. L. Genetic and autogenetic determinants of adult behavior in the rat. Journal of Comparative \& Physiological Psychology, 1963, 56, 423-428.

LEVINSON, B., \& REESE, H. W. Patterns of discrimination learning set in preschool children, fifth-graders, college freshmen, and the aged. Monographs of the Society for Research in Child Development, 1967, 32, 62-67.

RICCIO, D. C., ROHRBAUGH, M., \& HODGES, L. A. Developmental aspects of passive and active avoidance learning in rats. Developmental Psychobiology, 1968, 1, 108-111.

RICCIO, D. C., \& SCHULENBERG, C. J. Age related deficits in acquisition of a passive avoidance response. Canadian Journal of Psychology, 1969, 23, 429-437.

STEEL, R. G. D., \& TORRIE, J. H. Principles and procedures of statistics. New York: McGraw-Hill, 1960.

\title{
Effects of litter size on nursing time and weight of the young in guinea pigs*
}

\author{
JEFFREY J. STERN and GAYLE BRONNER \\ The University of Michigan, Dearborn, Mich. 48128
}

Fifteen female guinea pigs were observed with their offspring for Days 1-28 postpartum. The larger the litter (one to four animals), the greater the percentage of nursing time. With the exception of the four-animal litters, the smaller the litter, the greater the weight of the young. Finally, there was no relationship between litter size and the number of positive or negative nursing responses directed toward each pup.

Female rats rearing large litters behave less maternally than females rearing small litters (Seitz, 1959). Seitz's test of maternal behavior consisted of nine observational measurements; for each measure the female was rated on a scale of 0 through 4 , with 4 indicating strong maternal behavior. Females with a litter of 3 animals had a mean score of 21.33 , while females with a litter of 12 had a score of 13.92. Recently, Grota \& Ader (1969) confirmed Seitz's finding, using time with the young as their measure of maternal behavior. Total time with the litter decreased more rapidly for females with litters of 12 animals than for females with litters of 4 animals. In contrast, Schneirla, Rosenblatt, \& Tobach (1958) report that

*This research was funded by a Horace $\mathrm{H}$. Rackham School of Graduate Studies grant to J. J. Stern. The authors wish to thank George Petzer and Robert Donaldson for their valuable assistance throughout the experiment. with cats, the larger the litter, the greater the percentage of nursing time.

The present study examines the relationship between litter size and nursing behavior in a third species, the guinea pig.

\section{SUBJECTS AND MAINTENANCE}

The 15 females and their offspring were from a genetically heterogeneous stock reared in our laboratory. On the day of parturition the females ranged in age from 156-212 days. In all cases this was the female's first pregnancy. Guinea pig chow and water were available at all times. The laboratory had a thermostat which maintained the temperature at approximately $74^{\circ} \mathrm{F}$. The animals were on a natural light cycle with observations taking place from February 10 to May 5, 1970.

\section{PROCEDURE}

On the day of parturition 2 of the 15 females had their litter sizes altered. In one 

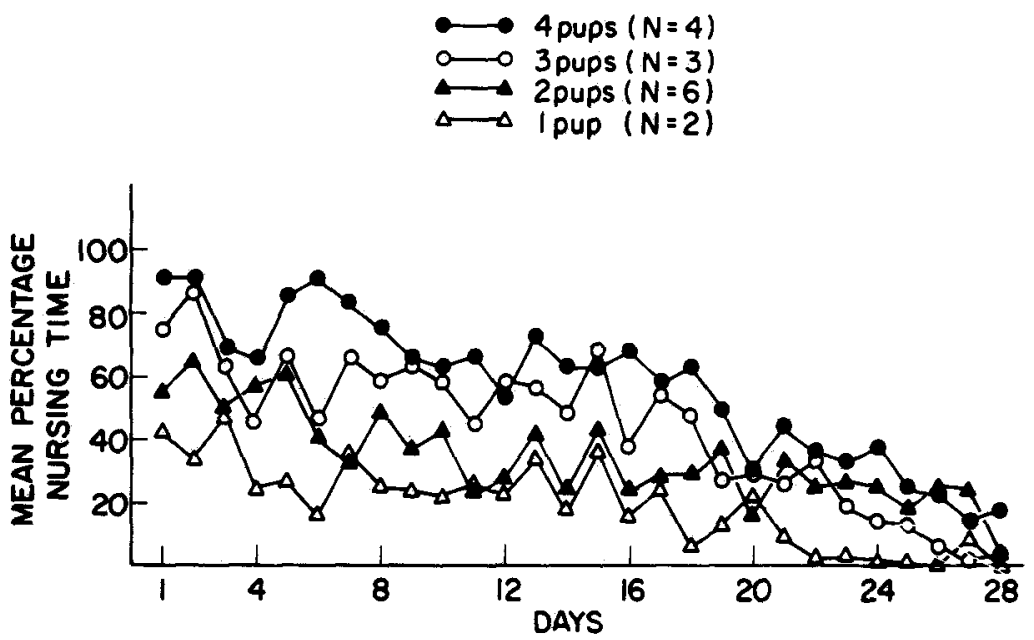

Fig. 1. Percentage of nursing time over the 28 days of observation.

case a 3-day old pup was given to a female, creating a litter of four animals; in the other case one piglet was removed, creating a litter of one animal. Continuing for the next four weeks, the female and its offspring were observed $30 \mathrm{~min}$ a day in their homecages. ${ }^{1}$ This observation schedule has been shown effective in the study of guinea pig nursing behavior (Stern \& Hoffman, 1970). The $30 \mathrm{~min}$ of observation consisted of three 10-min periods separated by intervals of from 1 to $9 \mathrm{~h}$. The usual interval between periods was $4 \mathrm{~h}$, with most observation taking place from 6:00 a.m. to 11:00 p.m. During each period the $E$ scored total nursing time, the number of positive responses, and the number of negative responses. A positive response is defined as any action by the female that increases the likelihood of nursing. For example, following an approach by the pups, the act of standing upright giving the pups access to the teats is scored as positive. Licking by the females of the pups' anogenital region is also scored as positive. During the postpartum period, guinea pig pups do not initiate urination or defecation, and it is believed that the stimulation provided by the females'

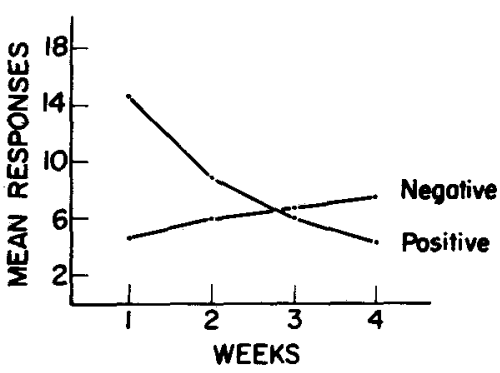

Fig. 2. Number of positive and negative responses for each of the 4 weeks of observation. licking induces the pups to void (Beach, 1966). A negative response is defined as any behavior by the female that tends to terminate or reduce the probability of nursing. If the pups are nursing at the start of an observation period and the female walks away, it will have a positive score of zero and a negative score of one. Again, if the pups attempt to nurse and the female pushes them aside, the female's behavior is scored negative. An approach by the pups to which the female does not actively respond is not scored even if the approach leads to nursing. In addition to these daily observations, the pups were weighed on the day of birth and every 7 days thereafter for the next 4 weeks. The piglets were weighed immediately following the second observation period.

\section{RESULTS AND DISCUSSION}

As shown in Fig. 1, there was a relationship between litter size and nursing time: The larger the litter size, the greater the percentage of nursing time. Mann-Whitney $U$ tests reveal that during each of the 4 weeks of observation, females with four pups nursed significantly more than females with three young. Females

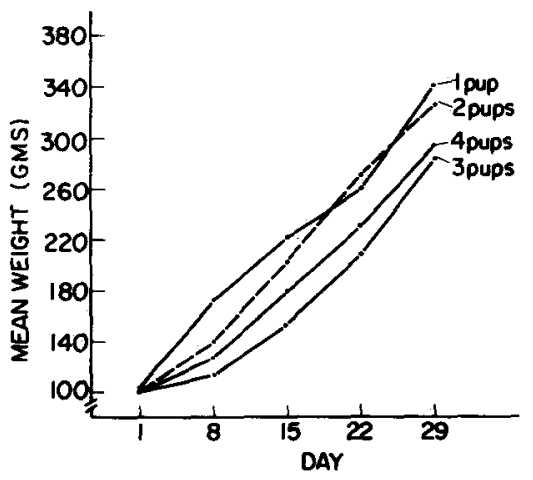

Fig. 3. The weights of the pups for Weeks 1-4. with two pups nursed more than females with one offspring. Finally, females with three pups nursed more than females with two pups for Weeks 1,2, and 3 but nursed less during Week 4.

There was no relationship between litter size and the number of positive or negative responses directed toward each offspring. However, certain females were found to be more responsive in both a positive and negative sense than others. For instance, one female with two young had a total of 61 positive and 33 negative responses, while a second female, also with two offspring, had 19 positive and 17 negative responses. An averaging of the positive and negative responses across litters reveals that while positive responses decrease in frequency over the nursing period, negative responses increase (Fig. 2).

On the day of birth there were no differences in the mean weights of the litters (Fig. 3). However, by Day 8 the weights had become different. In general, the smaller the litter, the greater the weight of the young. The one exception was the greater than expected weight of the animal with three siblings. Possibly this was due to the unusual health and vigor of their mothers; of eight females that reached term carrying four young, half died by Day 20 (only one female with one, two, or three young died during the nursing period), while in a fifth litter one of the pups (the smallest) died on Day 10; of three females that died during pregnancy, two were found at autopsy to be carrying four fetuses. These findings suggest that carrying and nursing four animals is a great strain on the female and that the animals. we observed with four young were those best able to adjust to the stress, i.e., the strongest and healthiest.

\section{REFERENCES}

BEACH, F. A. Ontogeny of "coitus-related" reflexes in the female guinea pig. Proceedings of the National Academy of Science, 1966, 56, 526-533.

GROTA, L. J., \& ADER, R. Continuous recording of maternal behavior in Rattus norvegicus. Animal Behaviour, 1969, 17, 722-729.

SCHNEIRLA, T. C., ROSENBLATT, J. S., \& TOBACH, E. Maternal behavior in the cat. In H. L. Rheingold (Ed.), Maternal behavior in mammals. New York: Wiley, 1963. Pp. 122-168.

SEITZ, P. F. D. The maternal instinct in animal subjects: I. Psychosomatic Medicine, 20, 1958, 215-226.

STERN, J. J., \& HOFFMAN, B. M. Effects of social isolation until adulthood on maternal behavior in guinea pigs. Psychonomic Science, $1970,21,15-16$.

\section{NOTE}

1. During the experiment, 21 observations were overlooked. Because these observations constitute such a small percentage of the total observation time $(1.7 \%)$, we did not specify the days or the groups affected. 